\title{
COMPARISON OF INTRAOCULAR PRESSURE CHANGES IN PATIENTS UNDERGOING CATARACT SURGERY, BASED ON LOCAL AND GENERAL ANAESTHESIA WITH LARYNGEAL MASK AIRWAY AND LARYNGOSCOPY TYPES
}

\author{
Asma Amiri Domari' ${ }^{1}$ Ali Sarkoohi², Yousef Taghavi³, Sayed Hamid Pakzad ${ }^{4}$, Hamid Bakhshi ${ }^{5}$ \\ ${ }^{1}$ Resident, Department of Anaesthesiology, Rafsanjan University of Medical Sciences, Rafsanjan, Iran. \\ ${ }^{2}$ Assistant Professor, Department of Anaesthesiology, Rafsanjan University of Medical Sciences, Rafsanjan, Iran. \\ ${ }_{3}^{3}$ Assistant Professor, Department of Ophthalmology, Rafsanjan University of Medical Sciences, Rafsanjan, Iran. \\ ${ }^{4}$ Assistant Professor, Department of Anaesthesiology, Rafsanjan University of Medical Sciences, Rafsanjan, Iran. \\ ${ }_{5}^{5}$ Academic Member, Molecular Medicine Research Center, Research Institute of Basic Medical Sciences, Rafsanjan University of Medical \\ Sciences, Rafsanjan, Iran.
}

\begin{abstract}
BACKGROUND
ABSTRACT

The control of hemodynamic status is important because it can affect intraocular pressure (IOP) in patients undergoing eye surgery. We wanted to compare IOP changes in patients undergoing cataract surgery based on local anaesthesia and general anaesthesia with laryngeal mask and laryngoscopy types.
\end{abstract}

\section{METHODS}

In this double-blind non-randomized controlled trial; 170 patients $40-80$ years old (ASA class I-II) candidates for elective cataract surgery enrolled to the study by convenience sampling method. After informed consent, patients were allocated to five groups A, B, C, D and E respectively. A) local anaesthesia, B) Macintosh laryngoscope, C) McCoy laryngoscope, D) video GlideScope and E) laryngeal mask airway. Systolic and diastolic blood pressures, mean arterial pressure, oxygen saturation and IOP were measured before, immediately and 5 minutes after airway intervention. IOP was measured with a Tono-Pen. Data was analysed by SPSS-16 using repeated measure ANOVA (Analysis of Variances), post hoc Tukey and chi-square tests. p-Value less than 0.05 was considered statistically significant.

\section{RESULTS}

115 patients (67.6\%) were female and 55 (32.4\%) were male. In the local anaesthetic group, mean of IOP decreased significantly after airway intervention $(\mathrm{p}=0.001)$. In laryngeal mask, Macintosh laryngoscope, McCoy laryngoscope and video GlideScope groups, IOP increased immediately and decreased 5 minutes after airway intervention $(p=0.001)$. Before the airway intervention, the mean of IOP in local anaesthetic group was higher than other groups $(p=0.012)$. Immediately and 5 minutes after air intervention, mean of IOP of the Macintosh laryngoscope was higher than other groups respectively $(p<0.001, p=0.029)$.

\section{CONCLUSIONS}

Our results showed that Macintosh laryngoscopy has more effects on IOP in patients undergoing cataract surgery in comparison to other anaesthetic methods.

HOW TO CITE THIS ARTICLE: Domari AA, Sarkoohi A, Taghavi Y, et al. Comparison of intraocular pressure changes in patients undergoing cataract surgery, based on local and general anaesthesia with laryngeal mask airway and laryngoscopy types. J. Evolution Med. Dent. Sci. 2019;8(22):1762-1766, DOI: 10.14260/jemds/2019/387

\section{BACKGROUND}

In eye surgeries, accuracy is important because visual sense is one of the main senses.(1) Cataract is one of the most commonly diseases that constitutes the highest number of ophthalmic surgeries.(2) Sometimes cataract surgery, like any other surgical procedure, requires general anaesthesia and in this condition intubation and laryngoscopy are necessary.(3)

Both laryngoscopy and intubation are painful that increase the physiological responses by stimulating autonomic reflexes, increasing the intraocular pressure (IOP),

'Financial or Other Competing Interest': None.

Submission 27-03-2019, Peer Review 18-05-2019,

Acceptance 23-05-2019, Published 03-06-2019.

Corresponding Author:

Ali Sarkoohi,

Assistant Professor,

Department of Anaesthesiology,

Rafsanjan University of Medical Sciences,

Rafsanjan, Iran.

E-mail: sarkoohiali8657@gmail.com

DOI: $10.14260 /$ jemds $/ 2019 / 387$

\section{(c) $(\mathrm{P})($}

and effect on the brain stem. The main effects of direct laryngoscopy and intubation are elevation of the sympathetic-adrenal activity, which leads to increase in the level of plasma catecholamine, heart rate, and arterial blood pressure. In fact, sensory impulses from the base of tongue, the epiglottis and the trachea go to the brain stem and stimulate vasomotor and cardiovascular system. This physiological pathway can increase the cardiac output.(4) IOP increases following sympathetic stimulation, due to arterial and venous contractions and increase in central venous pressure. Therefore, there is a positive relationship between IOP changes and individual hemodynamic status.(5) Increase in IOP is safe in healthy and closed eyes, but in the eye trauma or during eye surgery, including cataract, it can cause of bleeding and permanent vision loss.(6) Changes in the IOP or sudden and immediate high pressures may have negative effects on the vision system. In these cases, should be avoided starting both mechanical and pharmacological methods that increase IOP.(7) Hemodynamic changes in at risk patients can lead to complications. Airway intubation and medications methods are routine methods for decrease in the complications. The use of some medications such as opioids 
to control of hemodynamic changes can increases the risk of postoperative nausea, vomiting and the IOP. (8) Medical scientists are looking for find safe methods that have the least effect on IOP. In some studies, new methods have been compared with the routine method of intubation by laryngoscopes. The result of this studies was controversial. (9) Cataract is age-dependent disease, and patients who suffering from cataract are in developed age and consequently, cardiovascular disease is also higher in these patients. The aim of this study was to compare IOP changes in patients undergoing cataract surgery based on local and general anaesthesia with laryngeal mask and several types of laryngoscopy. In this study, the Tono-Pen electronic tonometer were used extensively to measure hemodynamic and IOP changes.

\section{METHODS}

The population of this Double-blind non-randomized controlled trial consists of patient's candidate for cataract surgery who referred to Moradi hospital (Rafsanjan, Iran) from March 2018 to January 2019. The sample size was calculated 34 people by formula (in each group) who were enrolled to study by convenience Sampling method.

\section{Inclusion Criteria}

Patients aged between 40 and 80 years, American Society of Anaesthesia (ASA) physical status classification I \& II.

\section{Exclusion Criteria}

Patients dissatisfied with getting involved in the study, cardiovascular, respiratory and neuromuscular disorders, disorders of the coagulation system, high aspiration risk, history of difficult intubation, chance of difficult intubation in clinical examinations (Mallampati score 4, stiff neck, mouth opening less than $35 \mathrm{~mm}$, and Thyromental Distance less than $65 \mathrm{~mm}$ ), patients with aspiration, vomiting, and cardiac arrest during anaesthesia, laryngoscopy and sedative use within 24 hours prior to the procedure were excluded.

Cardiovascular monitoring including electrocardiogram, pulse oximetry and blood pressure was performed for all patients in operating room. In this study, 5 groups were examined. A) Without induction, premedication was performed with midazolam (1 mg) and opioid (Fentanyl 1 $\mu \mathrm{g} / \mathrm{kg}$ ), and Tetracaine $0.5 \%$ eye drops were used to numb the eye before surgery. B) Intubation with direct laryngoscopy with Macintosh blade number 3. C) Intubation with direct McCoy laryngoscope with blade number 3. D) Intubation with video Glide Scope with blade number 3. E) Laryngeal mask. With the draw, the first patient was allocated in Group C. Thus, the second patient allocated in group D, the third patient in group E, the fourth patient in the group A and the fifth patient in the group B at the end. As premedication, Fentanyl ( $1 \mu \mathrm{g} / \mathrm{kg}$ ) and midazolam (1 mg) 5 minutes before inhalation was given to all patients $(n=170)$ before surgery. Patients in groups B, C, D and E were pre-oxygenation for 3 minutes $(100 \%)$. Then, anaesthesia performed with propofol $(2 \mathrm{mg} / \mathrm{kg})$ and atracurium $(0.5 \mathrm{mg} / \mathrm{kg})$. During maintenance, $50 \%$ nitrous oxide, $50 \%$ oxygen concentration and $1 \%$ Isoflurane gas were used. For all patients except the local group, the same drug was used. Anaesthesiologist was the same for everyone.
IOP in all five groups were measured before then immediately and 5 minutes after airway intervention using a Tono-Pen (Tono-Pen AVIA ${ }^{\circledR}$ Tonometer, Reichert Technologies Distributor, USA). Also, systolic, diastolic and mean arterial pressure was measured by patient care monitoring system (SAADAT Co, Iran) and heart rate (via monitoring) at the above times. Data analyser did not know the grouping.

\section{Statistical Analysis}

Data analysed by SPSS, 16 (SPSS, SPSS Inc, Chicago, Illinois) using repeated measure ANOVA (To assess changes in IOP at different stages of measurement in within group), Analysis of Variances (ANOVA) (To assess the changes in IOP at each stage between the groups), post hoc Tukey and chi-square tests. P-value less than 0.05 considered statistically significant.

\section{RESULTS}

From 170 patients, 115 (67.6\%) were female and 55 (32.4\%) were male. Mean \pm SD age was $63.59 \pm 8.87$ years. 59 patients (34.7\%) had ASA class I and 111 patients (65.3\%) were in ASA class II. There were no statistically significant differences in age, gender and ASA class between the study groups in the study ( $p>0.05)$. There was no significant difference in the risk of aspiration, difficult intubation, sedation and the nausea and vomiting in between the groups ( $p>0.05$ ).

The results of ANOVA test showed that the mean of IOP in local group (23.29 $\pm 12.30 \mathrm{mmHg})$ was significantly higher than other groups before airway intervention $(p=0.012)$. Immediately after airway intervention, the mean of IOP in Macintosh laryngoscope $(24.41 \pm 6.03 \mathrm{mmHg})$ group was significantly higher than other groups $(\mathrm{p}<0.001)$. In addition, 5 minutes after airway intervention, mean of IOP in Macintosh laryngoscope group was $19.29 \pm 5.04 \mathrm{mmHg}$. This IOP level was significantly higher than other groups $(\mathrm{p}=$ 0.029). Mean of IOP was compared in each group at different stages of measurement by repeated measure ANOVA. In each group, IOP changes were significant at different stages of measurement $(p=0.001)$ (Table 1$)$.

$$
n=\frac{\left(Z_{1-\frac{\alpha}{2}}\right)^{2}\left(\delta 1^{2}+\delta 2^{2}\right)}{(\mu 1-\mu 2)^{2}}
$$

The results of the Tukey post hoc test showed that before intervention, the mean of IOP in the local anaesthetic group was significantly higher than the laryngeal mask group $(\mathrm{p}=$ $0.003)$, the McCoy group ( $p=0.006)$ and the video GlideScope group $(p=0.002)$. Immediately after airway intervention, mean of IOP in the Macintosh laryngoscope $(\mathrm{p}<0.001)$, McCoy laryngoscope $(\mathrm{p}=0.012)$ and video GlideScope $(\mathrm{p}=$ 0.015 ) was higher than Local anaesthesia. Also, mean of IOP of Macintosh laryngoscope $(\mathrm{p}<0.001)$, McCoy laryngoscope $(p=0.015)$ and video Glide Scope $(p=0.018)$ was higher than laryngeal mask (Table 2).

\begin{tabular}{|c|c|c|c|c|}
\hline \multirow{2}{*}{ Groups } & \multicolumn{3}{|c|}{ IOP (mmHg) } & \multirow{2}{*}{ p-Value } \\
\cline { 2 - 5 } & Before & After & 5 min After & \\
\hline Local Anaesthesia & $23.29 \pm 12.30$ & $18.67 \pm 4.0$ & $17.26 \pm 3.87$ & 0.001 \\
\hline Laryngeal Mask & $16.14 \pm 4.72$ & $18.76 \pm 4.59$ & $15.11 \pm 2.80$ & 0.001 \\
\hline
\end{tabular}




\begin{tabular}{|c|c|c|c|c|}
\hline $\begin{array}{c}\text { Macintosh } \\
\text { Laryngoscope }\end{array}$ & $18.05 \pm 10.92$ & $24.41 \pm 6.03$ & $19.29 \pm 5.04$ & 0.001 \\
\hline $\begin{array}{c}\text { McCoy } \\
\text { Laryngoscope }\end{array}$ & $16.58 \pm 3.23$ & $22.64 \pm 4.12$ & $17.58 \pm 3.66$ & 0.001 \\
\hline $\begin{array}{c}\text { Video Glide } \\
\text { Scope }\end{array}$ & $15.91 \pm 3.51$ & $22.55 \pm 5.96$ & $17.26 \pm 6.08$ & 0.001 \\
\hline p-Value & 0.012 & $<0.001$ & 0.029 & \\
\hline Table 1. Comparison of Age and IOP Between and Within Groups \\
\hline \multicolumn{4}{|c|}{ Mean \pm SD, *: repeated measure ANOVA was used, **: ANOVA was used. } \\
\hline
\end{tabular}

\begin{tabular}{|c|c|c|c|}
\hline & \multirow{2}{*}{\begin{tabular}{|c|} 
Group Comparison \\
Local anaesthesia- laryngeal mask \\
\end{tabular}} & \multicolumn{2}{|c|}{ Mean diff $\mid p$-Value } \\
\hline \multirow{3}{*}{$\begin{array}{l}\text { Before } \\
\text { Intervention }\end{array}$} & & 7.14 & 0.003 \\
\hline & $\begin{array}{c}\text { Local anaesthesia- McCoy } \\
\text { laryngoscope }\end{array}$ & 6.70 & 0.006 \\
\hline & $\begin{array}{l}\text { Local anaesthesia- video Glide } \\
\text { Scope }\end{array}$ & 7.38 & 0.002 \\
\hline \multirow{6}{*}{$\begin{array}{c}\text { After } \\
\text { Intervention }\end{array}$} & $\begin{array}{l}\text { Local anaesthesia- Macintosh } \\
\text { laryngoscope }\end{array}$ & -5.73 & $<0.001$ \\
\hline & $\begin{array}{l}\text { Local anaesthesia- McCoy } \\
\text { laryngoscope }\end{array}$ & -3.97 & 0.012 \\
\hline & $\begin{array}{c}\text { Local anaesthesia- video Glide } \\
\text { Scope }\end{array}$ & -3.88 & 0.015 \\
\hline & $\begin{array}{c}\text { laryngeal mask- Macintosh } \\
\text { laryngoscope }\end{array}$ & -5.64 & $<0.001$ \\
\hline & $\begin{array}{l}\text { laryngeal mask- McCoy } \\
\text { laryngoscope }\end{array}$ & -3.88 & 0.015 \\
\hline & laryngeal mask- video Glide Scope & -3.79 & 0.018 \\
\hline \multicolumn{4}{|c|}{ Table 2. Comparison of IOP Between Groups } \\
\hline \multicolumn{4}{|c|}{ *: post hoc Tukey test was used } \\
\hline
\end{tabular}

\section{DISCUSSION}

The aim of this study was to compare the IOP changes in the patients undergoing cataract surgery based on local anaesthesia and general anaesthesia with laryngeal mask and laryngoscopy types. The results showed that the IOP in anaesthesia with the Macintosh laryngoscope, immediately after induction of anaesthesia, was higher than other anaesthetic methods. On the other hand, Macintosh laryngoscopy had a significant effect on the increase in IOP. McCoy Laryngoscope and video Glide Scope were also able to significantly increase the IOP immediately after airway intervention. It should be noted that the IOP of all study groups decreased significantly 5 minutes after airway intervention. In a study Agah and her colleagues found that Macintosh laryngoscopy can increased IOP and hemodynamic changes in comparison with the Optical Air Traq (OAT). Therefore, it is more harmful to anaesthesia in eye surgery, especially in the open ocular trauma. (10) Karaman et al in 2016 was reported the IOP changes was higher in Macintosh laryngoscope compared to the McGrath Series 5 video laryngoscope.(11) In a study Ahmad was reported Macintosh laryngoscope shown higher level in IOP at 1 min after intubation in comparison to Glide-Scope assisted tracheal intubation.(12) Das et al. in 2016 were found that Macintosh laryngoscopes had a significant increase in IOP and hemodynamic response to laryngoscopy and intubation in comparison with Airtraq laryngoscopy.(5) McCoy et al. showed that the use of the Macintosh blade had significantly more force being applied during laryngoscopy in compared to use of the McCoy blade.(13) Singhal et al. Found that the Macintosh laryngoscope create higher increase in IOP and hemodynamic responses to laryngoscopy and intubation in compare to the McCoy laryngoscope.(9) The results of the studies were similar to our founding. McCoy et al. Showed that using McCoy Blade improves laryngeal vision, this reduces pressure on laryngoscopy and intubation. As a result, hemodynamic reflexes are not clinically significant.(14) Haidry et al. Found that hemodynamic changes were shorter using McCoy's laryngoscope.(15) The results of the study by Lamb et al. Indicated that the change in IOP of anesthetized subjects with laryngeal mask at all times after measurement was significantly lower than that of the tracheal group.(16) Özhan et al. Demonstrated that the C-MAC Visional Cryptoscope can be used as the first choice for patients with high IOP who need general anaesthesia with intubation.(17) The intubation procedure for anaesthesia or mechanical ventilation increases the IOP. This mechanism is still unclear. Some scientists believe that cardiovascular activity during intubation are responsible for this status. Parandoosh in their study was found that in patients undergoing cataract surgery the IOP with general anaesthesia was lower than local anaesthesia.(18) The results of present study showed that the IOP in patients with intra-laryngeal mask anaesthesia had less variation in compared with other methods. Agha Alishiri et al. in 2010 reported that IOP of patients under laryngeal mask airway was less increased compare to tracheal intubation. Therefore, use of laryngeal mask airway was effective for ocular surgeries.(19) The laryngeal mask technique is completely different from the endotracheal intubation. In this method, laryngoscopy is not required to visualize the vocal cords. Also, the laryngeal mask does not go into the trachea and is instead located in the hypopharynx region. These factors make less stress to the patient and, therefore, better control of hemodynamic responses and IOP.(20) One of the other benefits of this technique is the deficiency of an increase in IOP due to its removal (In contrast of endotracheal tube).(21,22) Direct laryngoscopy and tracheal intubation always have been associated with stress. Stimulation following laryngoscopy and intubation can create sympathetic-adrenal reflex and this reflex can effect on heart rate and blood pressure and change hemodynamic responses.(23) The tracheal intubation stress was associated with an increase in IOP.(24) The mechanism of the secondary IOP increasing is due to increase in the sympathetic activity. Adrenergic stimulation can produce arterial and venous contractions and increases central venous pressure and leads to increased intravenous pressure, which is closely related to the IOP.(25) Different factors can effect on IOP, but the important factors are the aqueous humour dynamics, the changes in the choroidal blood volume (CBV), central venous pressure (CVP) and increased muscle tension of eyes. The sudden elevation in systolic blood pressure can make acute IOP until the aqueous humour flow moderates this pressure.(26) Obstruction in the central venous can create elevation in intravenous or hyperkinetic pressure, which this parameters increased CBV and IOP.(27) IOP may also be significantly affected by direct pressure on the eye, contraction of the extra-ocular muscles, contractions of the orbicularis oculi (OrbOc) muscles, eyelid closure, and congestion of the orbit veins. (28)

\section{CONCLUSIONS}

In this study, the same medications were used for induction of anaesthesia. Therefore, it can be concluded that Macintosh laryngoscopy has more effects on intraocular pressure in patients undergoing cataract surgery compared to other methods of airway management. Therefore, using laryngeal mask as against laryngoscopy with Macintosh, McCoy, and video GlideScope is preferable. 


\section{ACKNOWLEDGMENT}

We would like to thank all patients who participated in the study. We would like to thank the research deputy of medical school and staff of Moradi Medical, Rafsanjan University of Medical Sciences.

\section{REFERENCES}

[1] McGoldrick KE, Foldes PJ. General anaesthesia for ophthalmic surgery. Ophthalmology Clinics of North America 2006;19(2):179-91.

[2] Soleimani MR. A comparison of Cataract surgery complications under local anaesthesia plus intracameral Lidocaine with general anaesthesia. Feyz Journal of Kashan University of Medical Sciences 2002;6(2):13-7.

[3] Akbari GA, Entezariasl M, Amani F. Comparing the effects of remifentanil and alfentanil on the cardiovascular responses to the induction of anaesthesia and tracheal intubation in elderly patients. Journal of Ardabil University of Medical Sciences 2006;6(3):220-6.

[4] Jarineshin H, Sadeghizadeh N, Karimi Z, et al. Comparison of hemodynamic changes following intubation with Miller and Macintosh laryngoscope. Iranian Journal of Anesthesiology and Critical Care 2016;37(92):49-56.

[5] Das B, Samal RK, Ghosh A, et al. A randomised comparative study of the effect of Airtraq optical laryngoscope vs. Macintosh laryngoscope on intraocular pressure in non-ophthalmic surgery. Brazilian Journal of Anesthesiology (Elsevier) 2016;66(1):19-23.

[6] Cohen NH, Eriksson LI, Fleisher LA, et al. Miller's Anaesthesia. $8^{\text {th }}$ edn. Elsevier 2015: p. 3270.

[7] Ameri H, Esteki A, Ameri A. Mechanical modeling and studying on intraocular pressure of eye. Experimental Animal Biology 2014;2(4):43-9.

[8] Miller RD, Eriksson LI, Fleisher LA, Miller's Anaesthesia. $8^{\text {th }}$ edn. Saunders 2014.

[9] Singhal S, Singh K, Saharan N, et al. Intraocular pressure changes following laryngoscopy and intubation- McCoy versus Macintosh laryngoscope. Sri Lankan Journal of Anaesthesiology 2012;20(2):73-7.

[10] Agah M, Roodneshin F, Ghahramani M. Comparison of the effect of optical Air Traq vs. Macintosh laryngoscope on intra ocular pressure in ophthalmic surgery. Iranian Journal of Anesthesiology and Critical Care 2009;31(66):55-60.

[11] Karaman T, Dogru S, Karaman S, et al. Intraocular pressure changes: the McGrath video laryngoscope vs the Macintosh laryngoscope: a randomized trial. Journal of Clinical Anaesthesia 2016;34:358-64.

[12] Ahmad N, Zahoor A, Riad W, et al. Influence of GlideScope assisted endotracheal intubation on intraocular pressure in ophthalmic patients. Saudi Journal of Anaesthesia 2015;9(2):195-8.

[13] McCoy EP, Mirakhur RK, Rafferty C, et al. A comparison of the forces exerted during laryngoscopy. The Macintosh versus the McCoy blade. Anaesthesia 1996;51(10):912-5.
[14] McCoy EP, Mirakhur RK, McCloskey BV. A comparison of the stress response to laryngoscopy. The Macintosh versus the McCoy blade. Anaesthesia 1995;50(11):943-6.

[15] Haidry MA, Khan FA. Comparison of hemodynamic response to tracheal intubation with Macintosh and McCoy laryngoscopes. Journal of Anaesthesiology Clinical Pharmacology 2013;29(2):196-9.

[16] Lamb K, James MF, Janicki PK. The laryngeal mask airway for intraocular surgery: effects on intraocular pressure and stress responses. British Journal of Anaesthesia 1992;69(2):143-7.

[17] Çaparlar OC, Aydın BG, Sezer E, et al. A comparison of C-MAC videolaryngoscope and Macintosh laryngoscope in intraocular pressure changes, throat pain, intubation time and hemodynamic variables. The European Research Journal 2019.

[18] Parandoosh A. The survey and comparison of the effects of general anaesthesia and local anaesthesia on intraocular pressure in cataract surgery in one of the hospitals affiliated to Iran University of Medical Sciences. Tehran: Iran University of Medical Sciences 1992.

[19] Âlishiri AA, Naderi M, Jadidi K, et al. Comparing the effect of laryngeal mask airway and endotracheal tube insertion on intraocular pressure. Journal of Mazandaran University of Medical Sciences 2010;20(77):47-51.

[20] Duman A, Ögün CÖ, Ökesli S. The effect on intraocular pressure of tracheal intubation or laryngeal mask $\mathrm{k}^{\mathrm{TM}}$ insertion during sevoflurane anaesthesia in children without the use of muscle relaxants. Pediatric Anaesthesia 2001;11(4):421-4.

[21] Bhardwaj N, Yaddanapudi S, Singh S, et al. Insertion of laryngeal mask airway does not increase the intraocular pressure in children with glaucoma. Paediatric Anaesthesia 2011;21(10):1036-40.

[22] Ziyaeifard M, Azarfarin R, Massoumi G. A comparison of intraocular pressure and hemodynamic responses to insertion of laryngeal mask airway or endotracheal tube using anaesthesia with propofol and remifentanil in cataract surgery. Journal of Research in Medical Sciences: The official Journal of Isfahan University of Medical Sciences 2012;17(6):503-7.

[23] Nishikawa K, Hukuoka E, Kawagishi T, et al. Efficacy of the Airtraq ((R)) laryngoscope with a fiberoptic bronchoscope compared with that of Airtraq((R)) alone for tracheal intubation: a manikin study. Journal of Anaesthesia 2011;25(1):93-7.

[24] Mostafa SM, Wiles JR, Dowd T, et al. Effects of nebulized lignocaine on the intraocular pressure responses to tracheal intubation. British Journal of Anaesthesia 1990;64(4):515-7.

[25] Kilickan L, Baykara N, Gurkan Y, et al. The effect on intraocular pressure of endotracheal intubation or laryngeal mask use during TIVA without the use of muscle relaxants. Acta Anaesthesiologica Scandinavica 1999;43(3):343-6. 


\section{Jemds.com}

[26] Schreuder M, Linssen GH. Intraocular pressure and anaesthesia. Direct measurements by needling the anterior chamber in the monkey. Anaesthesia 1972;27(2):165-70.

[27] Macri FJ. Vascular pressure relationships and the intraocular pressure. Archives of Ophthalmology (Chicago, Ill: 1960) 1961;65(4):571-4.
Original Research Article

[28] Cunningham AJ, Barry P. Intraocular pressure physiology and implications for anaesthetic management. Canadian Anaesthetists' Society Journal 1986;33(2):195-208. 